\section{ARS Tech}

Authors retain copyright

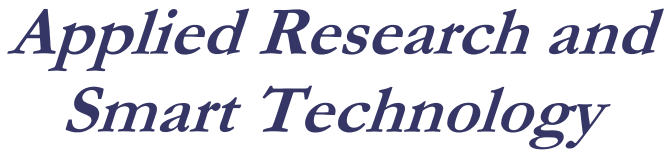

Journal homepage: www.journals2.ums.ac.id/index.php/arstech

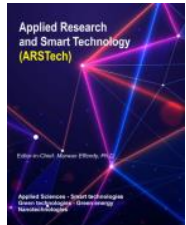

ISSN 2722-9645

\title{
General design criteria for neonatal temperature monitoring sensor using "smart material" conducting polymer development: A review
}

\author{
Nor Syamimi ${ }^{1, *}$, Shuhaida Yahud ${ }^{2}$ \\ ${ }^{12}$ Biomedical Electronic Engineering, School of Mechatronic, Perlis, Malaysia. \\ ${ }^{*}$ Corresponding author: shuhaidayahud@unimap.edu
}

Permalink (DOI): $\underline{\text { https://doi.org/10.23917/arstech.v2i1.185 }}$

\begin{abstract}
ARTICLE INFO
Article history:

Received 9 September 2020

Revised 23 January 2021

Accepted 18 June 2021

Available online 23 June 2021

Published regularly 30 June 2021

Keywords:

Conducting material

Flexible temperature sensor

Neonates

Patient monitoring

Thermistor

ABSTRACT

Surface thermistors are currently being used in patient monitoring, including temperature monitoring among neonates. However, these thermistors are reported as being mechanically rigid. This review article aims to provide researchers with a guide to better design a flexible neonatal temperature monitoring sensor. A literature search was conducted to obtain available literature on temperature sensors with specific attention to designing flexible temperature sensors. The achievement of a flexible-type thermistor for neonates requires a basic understanding of the thermistor. Also, the conducting polymer material being used and the rationale for their placement. The updated technology in thermistors should be made flexible for the ease of neonates during monitoring. Careful considerations for the design and conduct of flexible temperature sensor research, as outlined in this review, would help to enhance the quality and comparability of future research studies. Considerations for efficient neonatal temperature monitoring and protection include accuracy, sensor size, weight, material, and sensor placement. Flexible sensors could be the alternative to conventional bulky and stiff temperature sensors.
\end{abstract}

\section{INTRODUCTION}

Neonatal monitoring means monitoring vital physiological parameters [1] of premature infants, fullterm infants critically ill, and a combination thereof [2]. Generally, continuous monitoring of neonates' vital signs and parameters is essential in neonatal intensive care units (NICUs) [3]. Special care and attention to the neonate's vital signs are crucial, including body temperature, heart rate, breathing rate, body temperature, respiration, blood oxygen saturation, and blood pressure, as premature infants are exposed to the risk of developing adverse conditions. Thus, it must sustain individuals' vital signs and physiological parameters $[4,5]$. Their organs are not mature enough to allow expected postnatal survival [6].

Effective neonatal care in the NICUs prevents possible clinical implications such as apnea, hypoglycaemia, sepsis or sepsis-like infection, seizure, 
arterial hypotonia, bradycardia, and hypoxia $[7,8]$. Other complications include difficulty breathing, increased glucose utilisation, post-delivery acidosis, and many more [9].

Body temperature status is one of the necessary indicators for neonates [10], especially pre-term neonates. Continuous monitoring of body temperature helps with the early identification of temperature instability [11]. Deviation from an average body temperature indicates that there is a pathological condition [9]. It is essential to accurately measure the body temperature of neonates as thermoregulation can influence their survival [11]. As the survival rate of neonates has increased significantly in the last decades, the quality of life of neonatal intensive care unit (NICUs) infants has also become an important issue [12].

The maturation of temperature sensing technology has been anticipated for over 1,000 years ago. Around 400 B.C, physicians placed their hands on the patient's forehead and utilised their sense of touch to estimate their body temperature [13]. Later, in the 17th century, a simple thermometer was devised, the first objective biomedical sensing device. Since then, temperature sensors have become essential in healthcare services and realise the importance of scientific developments and advances in biomedical technologies.

In recent years, a wide range of temperature monitoring and sensors for patient monitoring have been developed. The neonatal health monitoring technology development includes a diversity of wearable devices [7] [10], such as smart jackets [10] and intelligent fabric. For example, Chen et al., 2010 introduced a wearable device incorporating a negative temperature coefficient (NTC) type of temperature sensor, a thermistor, to their bright infant jacket.

The traditional method of neonatal temperature monitoring is by direct supervision of the healthcare personnel using a thermometer [14]. This method is sometimes difficult to identify fundamental temperature changes, which may be of concern. In addition, the response time of the thermometer is inadequate, and it took at least 9 seconds for a constant thermometer reading from room temperature to $50{ }^{\circ} \mathrm{C}$ [15]. Another issue is that the glass mercury thermometer is due to the potential hazard with mercury [9]. Furthermore, continuous monitoring of the neonates cannot provide due to the measurement mechanism that requires the healthcare provider to take the temperature measurement repeatedly. The measure of core body temperature through rectal using the thermometer has been reported, but it did not provide continuous monitoring. Furthermore, the rectal measurement method is invasive and potentially risks rectal injury [11] due to repeated rectal temperature measurements.
To overcome the problem, later, the use of surface temperature sensors is introduced. Any device that senses temperature information is termed a temperature sensor, with a recordable, usually electrical or optical [13]. Temperature sensors achieve continuous temperature monitoring. Thus, the neonate's body temperature information can be closely monitored. The skin temperature sensor is preferable for temperature monitoring as it is non-invasive and reflects the core body temperature [11]. Continuous temperature measurements can also be retrieved using an embedded temperature in an oesophageal tube [16] as soon as the baby is delivered.

Thermocouples, RTDs (resistance temperature detectors), and thermistors are commonly researched temperature sensors. The intrinsic principles associated with these sensors have their advantages and disadvantages, shown in Table 1, Table 2 and Table 3 . The applications of these types of sensors in the medical field are demonstrated in Figure 1.

Table 1. Thermocouple.

\begin{tabular}{|c|c|}
\hline Characteristics & $\begin{array}{l}\text { It consists of two wires of different } \\
\text { metals connected at two points. } \\
\text { The varying voltage between these } \\
\text { two points reflects proportional } \\
\text { changes in temperature. }\end{array}$ \\
\hline Advantages & $\begin{array}{l}\text { Inexpensive, durable, and able to } \\
\text { operate across the broadest } \\
\text { temperature range (from }-200{ }^{\circ} \mathrm{C} \\
\text { to } 1750{ }^{\circ} \mathrm{C} \text { ). }\end{array}$ \\
\hline Disadvantages & $\begin{array}{l}\text { One of the most challenging } \\
\text { sensors to operate with low } \\
\text { accuracy and small output voltage } \\
\text { requires precise amplification. Also, } \\
\text { susceptibility to external noise over } \\
\text { long wires }\end{array}$ \\
\hline
\end{tabular}

Table 2. Resistance temperature detectors (RTDs).

\begin{tabular}{ll}
\hline Characteristics & $\begin{array}{l}\text { Measures temperature by } \\
\text { correlating the resistance of the } \\
\text { RTD element with temperature }\end{array}$ \\
& $\begin{array}{l}\text { Offer a wide range of temperature } \\
\text { measurements (smaller than } \\
\text { thermocouples) and provide } \\
\text { accurate and repeatable } \\
\text { measurements }\end{array}$ \\
& $\begin{array}{l}\text { Expensive, slower response time } \\
\text { and require an excitation }\end{array}$ \\
&
\end{tabular}


Table 3. Thermistors.

\begin{tabular}{ll}
\hline Characteristics & A thermally sensitive resistor \\
\hline Advantages & $\begin{array}{l}\text { Durable, small and exhibits a } \\
\text { large, predictable, and precise } \\
\text { change in resistance correlated to } \\
\text { variations in temperature }\end{array}$
\end{tabular}

Disadvantages Nonlinear outputs
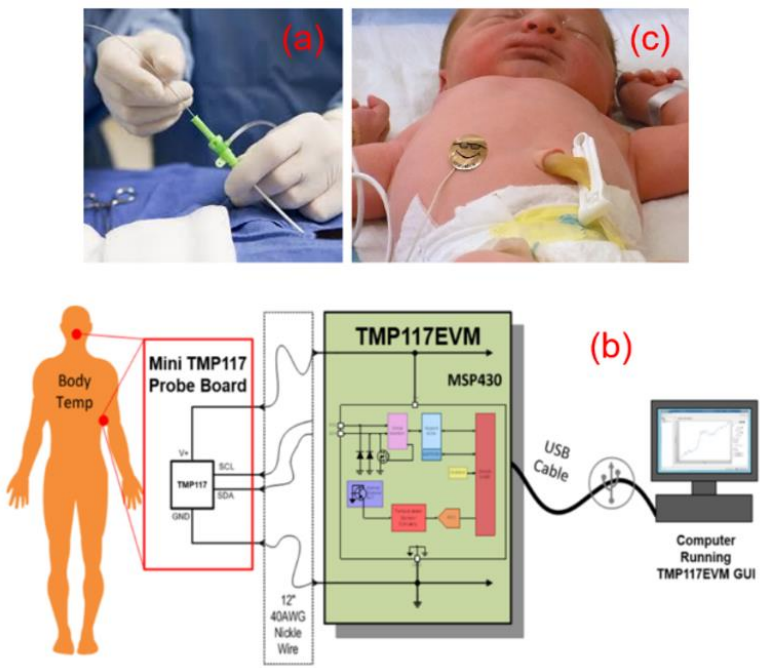

Figure 1. (a) Thermocouples for a catheter to measure temperature [17]. (b) Body temperature measurement system using RTDs [18]. (c) An infant is attached to

the thermistor probe using a reflective foil [19].

This paper aims to review thermistor-type temperature sensors for neonatal monitoring. A thermistor is a thermal resistive type of temperature sensor. The thermistor is a temperature-dependent resistor with steep rising or falling resistance characteristics [20]. It displays significant changes in resistance in proportion to small changes in temperature. The relationship between the thermistor resistance $R_{t}$ and absolute temperature $T(K)$ is in equation (1) [21]. Note that $\beta$ and $T_{0}$ are in Kelvin. The temperature coefficient is not constant but varies with temperature changes [22].

$$
R_{t}=R_{0} e^{\left[\frac{\beta\left(T_{0}-T\right)}{T T_{0}}\right]}
$$

where:

$\beta=$ material constants

$T_{0}=$ standard reference of temperature

There are two types of thermistors. One with steep rising resistance characteristics is described as having a Positive Temperature Coefficient (PTC) of resistance, while the other with a falling resistance characteristic has a Negative Temperature Coefficient (NTC). The PTC-type thermistor is nonlinear, whereas the NTC-type thermistor follows a roughly logarithmic law with no violent changes in resistance [22]. The primary output of the thermistor is electrical in nature and hence easier to integrate into a chip for further signal processing [23]. Figure 2 depicts a typical circuit for a thermistor.

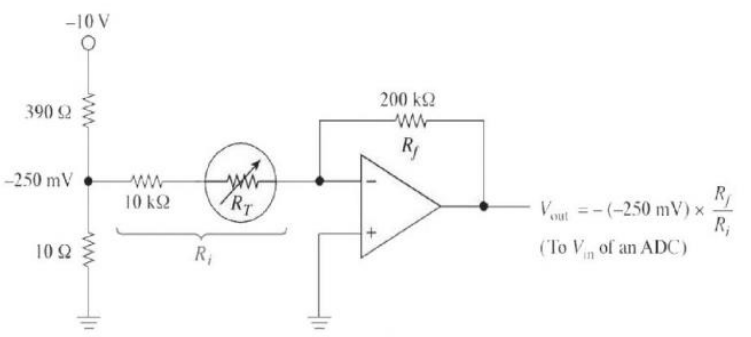

Figure 2. Circuit to convert thermistor ohm to DC voltage [24].

Most neonates' body temperature is monitored using a ceramic-based thermistor taped on the skin surface using adhesive tape [12]. However, existing devices' bulky and non-flexible nature will limit the duration of comfortable use [25] and be inconvenient to wear for a long time, restricting their applications. In addition, the sticky and adhesive tape and the presence of wires, on the other hand, will be painful when removed and discomfort for the neonates [12].

This paper focuses on a flexible skin surface thermistor type of temperature sensor. Current thermistor-based medical sensor technologies still have not attained the mechanical properties of being flexible. This study is inspired by flexible and thin-film electronics technology and the importance of neonatal temperature sensing in medical applications. Advanced flexible electronics could make continuous contact with soft and curved infant bodies. Hence, potentially initiating longterm monitoring of neonatal temperature changes.

Constructing a conductive and flexible sensor for neonatal temperature monitoring is challenging yet interesting. More specifically, a qualified, flexible sensor design must also consider several criteria, and the outward appearance should meet the aesthetic requirements [7]. A comparison is also made among different clinical thermistors regarding the sensor's responding time and accuracy. Pertinent journal papers and research articles were also reviewed to justify this review paper's emphasis on summarising thermistors design's criteria of flexible thin-film (thin-film substrate size less than $2 \mu \mathrm{m}$ [5]) technology currently undergoing assessment. Neonatal monitoring sensors should also be non-invasive [7]. General criteria for temperature sensors or thermistors are discussed as follows. 


\section{GENERAL DESIGN CRITERIA FOR NEONATE'S TEMPERATURE SENSOR}

This section emphasises the essential design criteria and considerations for neonatal temperature monitoring. Several criteria must be met to achieve flexible sensor requirements. The desirable provision of the adjustable temperature sensors includes high sensitivity, fast response, wide-working temperature range, and lightweight [14].

\subsection{Sensor's Accuracy and Response Time}

One of the major concerns in designing body temperature sensors is accuracy. Sensor accuracy represents how close the temperature is to the actual value. A suitable temperature sensor should possess high accuracy and sensitivity [26] to record the infant skins' temperature. Thin and flexible skin surface sensors must have sufficient sensitivity and accuracy due to their attachment to the non-planar skin surface with motion [26] The accuracy can be addressed by picking a temperature sensor with high measurement precision.

Another critical factor is the sensor's response time. A temperature sensor should be responsive to temperature changes with a relatively fast speed and accuracy of $0.1^{\circ} \mathrm{C}$ from 37 to $39^{\circ} \mathrm{C}$ and $0.2^{\circ} \mathrm{C}$ both below $37^{\circ} \mathrm{C}$ and above $39^{\circ} \mathrm{C}[26]$. The sensor's response speed is determined by the sensor's amount of thermal mass [18]. The sensor's size and placement will affect the response time; thus, both criteria must be taken. While the sensor's size also impacts the design, the sensor size and thickness determine the thermal response time. Therefore, the sensor's weight and size need to be small, and it should not hinder the user's movements and actions, especially in infants [7]. The small dimensions of most bead, disc, and chip thermistors used for resistance thermometry ensure a rapid response to temperature changes.

This feature is handy for temperature monitoring and control systems requiring quick feedback [27]. A comparison is made among different clinical thermistors regarding the sensor's responding time and accuracy, depicted in Table 4. There are several clinical skin probe sensors for neonatal monitoring, but not enough data from the thermistor's datasheet for reference. Other characteristics are the sensor's repeatability and stability against surrounding influences [26]. The overall design needs to be considered to achieve these requirements, such as size, thickness, and material choices. Also, the patient monitoring temperature sensors should possess an operating temperature range of $\left(25^{\circ} \mathrm{C}\right.$ to $\left.40^{\circ} \mathrm{C}\right)$ [26].
Table 4. The accuracy and response time of some clinical temperature sensors.

\begin{tabular}{|c|c|c|c|}
\hline Thermistor Types & Accuracy & $\begin{array}{l}\text { Response } \\
\text { Time }\end{array}$ & Tolerance \\
\hline $\begin{array}{l}\text { Body surface NTC } \\
\text { sensor probe, } \\
\text { Hefei Jingpu } \\
\text { Sensor Technology }\end{array}$ & $\pm 0.1{ }^{\circ} \mathrm{C}$ & 2 seconds & - \\
\hline $\begin{array}{l}\text { Skin/surface } \\
\text { probe, model } 427 \text {, } \\
\text { TE Connectivity }\end{array}$ & $\pm 0.1{ }^{\circ} \mathrm{C}$ & $\begin{array}{l}\text { extremely } \\
\text { fast }\end{array}$ & $\begin{array}{l}25 \text { to } 45 \\
{ }^{\circ} \mathrm{C}\end{array}$ \\
\hline $\begin{array}{l}\text { NovaTemp skin } \\
\text { temperature sensor }\end{array}$ & $\pm 0.2^{\circ} \mathrm{C}$ & rapid & $\begin{array}{l}25 \text { to } 50 \\
{ }^{\circ} \mathrm{C}\end{array}$ \\
\hline $\begin{array}{l}\text { PASCO } \\
\text { skin/surface } \\
\text { temperature probe }\end{array}$ & $\pm 0.5^{\circ} \mathrm{C}$ & - & $\begin{array}{c}-10 \text { to } 70 \\
\pm{ }^{\circ} \mathrm{C}\end{array}$ \\
\hline $\begin{array}{l}\text { LMT70 } \\
\text { temperature sensor }\end{array}$ & $\pm 0.1{ }^{\circ} \mathrm{C}$ & - & $\begin{array}{c}20 \text { to } 42 \\
{ }^{\circ} \mathrm{C}\end{array}$ \\
\hline
\end{tabular}

\subsection{Placement of Sensors}

Package and placement can impact the response time and conduction path; both are critical for effective temperature design. In infant temperature sensing, the specific site of body temperature recording must be selected carefully to truly reflect the patient's temperature [4]. During thermoregulation, the body heat is generated mainly in the deep organs, especially the liver, brain, heart, and skeletal muscles' contractions. Hence, the active organs will either increase in temperature or decrease in weather. For example, the liver is one of the most active organs, where the temperature around the liver is relatively high [10]. Therefore, the skin temperature above the liver of infants under radiant warmer in the NICU is usually measured. Figure 3 shows a wearable sensor demonstrated on a baby doll where the thermistor is set between the infant's back and the mattress of the incubator [10].

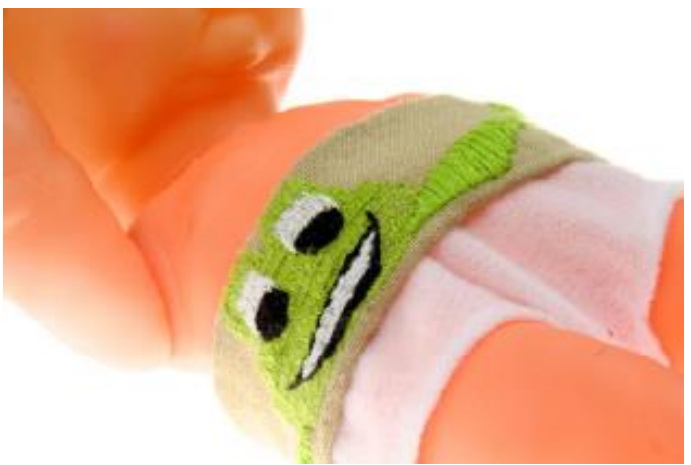

Figure 3. The proposed wearable sensor placement[10]. 
The skin temperature of infants can be monitored while the sensor probe attaches to the arm [25], abdomen, flanks, chest, or back area [28]. They are usually measured by using a surface thermistor [10] or an infrared light absorption technique [29] under the direct supervision of nurses, parents, and clinicians [7]. For example, figure 4 shows a pre-term infant in an incubator where the thermistor probe is attached to the infant's back [30].

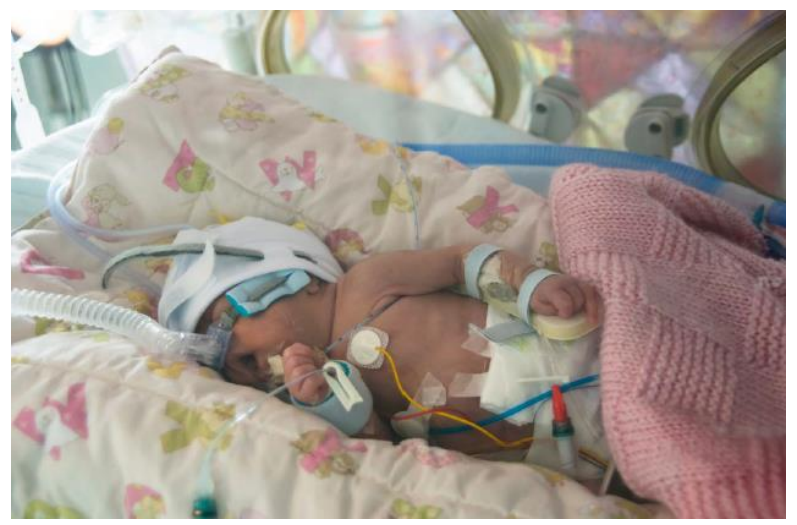

Figure 4. A baby in the neonatal intensive care unit[30].

Based on a study done by Pouy and Chehrzad, 2018, they concluded that the best measurement site for measuring skin temperature in NICUs neonates is the right hypochondrium and right axillary areas [11]. Their finding is based on the diagnostic clinical trial done on 203 premature neonates who were cared for under a radiant warmer, where the temperature probe was placed at seven different locations. In addition, a temperature sensor should not be placed above bones [10]. As for localised temperature sensing, the sensor could be placed at the infected area on the skin surface or readily available devices such as catheters for intravenous temperature monitoring.

\subsection{Body Temperature Range}

If body temperature information needs to be achieved using a temperature monitoring device, sensory inputs similar to the infant's normal and abnormal body temperature must provide the necessary feedback to explore further and analyse physicians. For example, a review reported that the lethal limits of body temperature range from as low as $26^{\circ} \mathrm{C}\left(78.8^{\circ} \mathrm{F}\right)$ to a high of $43^{\circ} \mathrm{C}$ $(109.4 \mathrm{oF})[31]$.

Usually, temperatures within this limit do not cause thermal injury to body tissues. Likewise, patients with a temperature increase too far above average may be at risk of seizures, brain damage, and other complications. Unlike adults, children and babies have a little higher temperature value in a range of $36.6^{\circ} \mathrm{C}\left(97.9^{\circ} \mathrm{F}\right)$ to $38^{\circ} \mathrm{C}$ $\left(100.4^{\circ} \mathrm{F}\right)$. According to The World Health Organization (WHO) (1997), the range for the average temperature of an infant is $36.5^{\circ}$ to $37.5^{\circ} \mathrm{C}$ [16]. Although the core body temperature is typically maintained at around $37^{\circ} \mathrm{C}$, the skin surface temperature is slightly lower and depends on location, gender [32], and measurement time [31]. Table 5 shows the range of premature infant temperatures according to the measurement location.

Table 5. The general temperature ranges for premature infants [16].

\begin{tabular}{cc}
\hline $\begin{array}{c}\text { Measurement } \\
\text { location }\end{array}$ & Temperature \\
\hline Rectal & $\left(36.5\right.$ to $\left.37.5^{\circ} \mathrm{C}\right)$ \\
Skin & $\left(36.2\right.$ to $\left.37.2^{\circ} \mathrm{C}\right)$ \\
Axillary & $\left(36.5\right.$ to $\left.37.3^{\circ} \mathrm{C}\right)$ \\
\hline
\end{tabular}

\subsection{Material Selection}

Correct material selection is not less important in building a temperature sensor. Flexible temperature sensors and thermistor types of sensors gathered considerable interest, and efforts have been made in various kinds of material. Table 6 shows examples of flexible and wearable temperature sensors and thermistors. However, scholars in these fields have not adequately addressed flexible, mechanically robust, and sensitive sensors using PPy as sensing material and P.U. as a substrate's sensor.

\subsection{Conducting Polymers (C.P.s) as Sensing Material}

Conducting polymers (C.P.s) have received increasing attention over the past decades owing to their electrical properties similar to those metals and traditional semiconductors [37], labelled as "synthetic metals" in the late 1970 s $[37,38]$. There are at least 20 types of C.P.s available [39]. C.P.s have tremendous technological potential for the development of sensors. C.P.s are conducting polymers in which a conducting material is dispersed in a non-conductive polymer (organic polymer) [37,40]. C.P.s can conduct electricity [41]. When it is doped and is distinguished from other types of polymers due to its conjugated double bond structure [39], described by sigma $(\sigma)$ and pi $(\pi)$ bonds. In comparison, the $\sigma$ electrons are fixed and immobile due to the formation of covalent bonds [42]. Among the listed conductive polymers, Polypyrrole (PPy), Polyaniline (PAni) and Poly (3,4-Ethlynedioxythiophene (PEDOT) are the most promising conductive polymer, arguably the most studied conductive polymer, reflected by the amount of publication surrounding its properties [39] and their applications in the Biomedical field [43]. 
Table 6. Thermal sensor and thermistor specification for temperature monitoring

\begin{tabular}{|c|c|c|c|c|c|}
\hline Sensor Material & $\begin{array}{l}\text { Substrate } \\
\text { Material }\end{array}$ & Key Features & Limitation(s) & Final Product & Ref. \\
\hline Graphene & $\begin{array}{l}\text { Polydimethy } \\
\text { lsiloxane } \\
\text { (PDMS) }\end{array}$ & $\begin{array}{l}\text { Flexible and } \\
\text { stretchable }\end{array}$ & $\begin{array}{l}\text { Sensitivity } \\
\text { fluctuation } \\
\text { under Strain }\end{array}$ & & [33] \\
\hline $\begin{array}{l}\text { Nickel Oxide } \\
(\mathrm{NiO})\end{array}$ & $\begin{array}{l}\text { Polyimide } \\
\text { film }\end{array}$ & $\begin{array}{l}\text { High-sensitivity, } \\
\text { scalable } \\
\text { manufacturing }\end{array}$ & $\begin{array}{l}\text { Not } \\
\text { stretchable, } \\
\text { poor material } \\
\text { adhesion }\end{array}$ & & [34] \\
\hline $\begin{array}{l}\text { Nickel Oxide } \\
\qquad(\mathrm{NiO})\end{array}$ & Polyimide & $\begin{array}{l}\text { Mechanically } \\
\text { robust }\end{array}$ & $\begin{array}{l}\text { Unknown } \\
\text { sensitivity }\end{array}$ & & [35] \\
\hline $\begin{array}{c}\text { Organic conductors } \\
(\text { BEDT-TTF })_{2} X_{3} \\
\text { (Bis[ethylenedithio] } \\
\text { tetrathiafulvalene, } \\
\left.X_{3}\right)\end{array}$ & $\begin{array}{l}\text { Polycarbona } \\
\text { te (P.C.) } \\
\text { film } \\
\text { containing } \\
\text { eight wt } \% \text { of } \\
\text { BEDT-TTF }\end{array}$ & $\begin{array}{l}\text { Lightweight and } \\
\text { accuracy of } \\
0.005\end{array}$ & $\begin{array}{l}\text { Unknown } \\
\text { sensitivity }\end{array}$ & & [36] \\
\hline
\end{tabular}

\subsection{Flexible Encapsulation Material (Substrate)}

In most bio-hybrid technology, the primary thin film substrates are usually fabricated using elastomeric material to provide cell adhesion and proliferation such as Polydimethylsiloxanes (PDMS), Polymethylmethacrylate (PMMA), Polyurethane (P.U.), Polyester, Polycarbonate [44], polyimide (P.I.) and polyethene terephthalate (PET) [26]. In addition, encapsulation of the thermistor is essential as it needs to provide adequate barriers to reduce moisture intake and protect the thermistor from later processing [35]. PDMS material is the most used substrate [26], but P.U. is prevalent [45].

\section{OTHER POTENTIAL BIOMEDICAL APPLICATIONS}

Other than being used for neonates, the criteria can be applied to design flexible or wearable thermistors for other potential biomedical applications. Small in size, thin, flexible, and lightweight could also be helpful in telemedicine due to its ability to follow the body's contours. This sensor could also be applied to catheters making it a sensing catheter to assist surgical interventions such as measuring temperature during the cardiopulmonary bypass circuit. Also, to attach it to catheters for applications such as Pulmonary Artery Characterization (PAC), Foley catheters, and Intravenous therapy. The small size and thin thermistors could also be wearable and embedded into babies' fabric, shoe soles for diabetes patients' feet, or attached to the tracheal tube for paediatric patients. Additionally, ongoing studies in temperature monitoring with flexible and stretchable formats open up other potential areas, such as artificially electronic skins [26].

\section{CONCLUSION}

This article sought to provide a quick guide to the body of literature outlining the potential criteria in designing a temperature sensor, a thermistor. Careful considerations for the design and conduct of thermistor research will enhance future research studies quality and comparability, especially in thin-film and flexible temperature sensors in neonatal monitoring. The use of 
skin surface thermistors for neonates has grown substantially over the years. Moreover, neonatal healthcare providers are primarily still using ceramic-based thermistors. Future directions include the current study to fabricate a conducting polymer-based flexible thermistor for neonatal monitoring. An additional circuit will be added to analyse the overall sensor's performance, thus can yield a more optimised design. However, it is still challenging to fabricate a flexible temperature sensor with a reproducible sensing response in an appropriate temperature range.

\section{CONFLICTS OF INTEREST}

No conflict of interest affects this publication.

\section{ACKNOWLEDGEMENT}

The authors acknowledge the School of Mechatronic Engineering, Universiti Malaysia Perlis, for the postgraduate facilities. Also, to the school of Nano Electronic Engineering, Universiti Malaysia Perlis, for the laboratory facilities.

\section{REFERENCES}

[1] L. Suresh, N.A. Latha, B.R. Murthy, K.T. Alam, and K.J. Babu, "Neonatal monitoring system", Int. Journal of Engineering Research and Applications, Vol. 4, No. 7, pp. 12-15, 2014.

[2] V. Somerset, "Intelligent and biosensors", BoDBooks on Demand, 2010.

[3] A.K. Abbas, K. Heimann, K. Jergus, T. Orlikowsky, and S. Leonhardt, "Neonatal non-contact respiratory monitoring based on real-time infrared thermography", Biomedical engineering online, Vol. 10, No. 1, pp. 1-17, 2011. https://doi.org/10.1186/1475-925X-10-93

[4] J.G. Webster, "Medical instrumentation application and design", John Wiley \& Sons, 2009.

[5] K. Xu, Y. Lu, and K. Takei, "Multifunctional skininspired flexible sensor systems for wearable electronics", Advanced Materials Technologies, Vol. 4, No. 3, pp. 1800628, 2019. https://doi.org/10.1002/admt.201800628

[6] T.A. Tisa, Z.A. Nisha, and M.A. Kiber, "Design of an enhanced temperature control system for neonatal incubator", Bangladesh Journal of Medical Physics, Vol. 5, No. 2013.

\section{https://doi.org/10.3329/bjmp.v5i1.14668}

[7] Z. Zhu, T. Liu, G. Li, T. Li, and Y. Inoue, "Wearable sensor systems for infants", Sensors, Vol. 15, No. 2, pp. 3721-3749, 2015. https://doi.org/10.3390/s150203721

[8] T. Yamada, and T. Watanabe, "Development of a small pressure-sensor-driven round bar grip measurement system for infants", The SICE Annual Conference 2013, pp. 259-264, 2013. https://doi.org/10.1299/kikaic.79.743

[9] J. Smith, "Thermoregulation and temperature taking in the developing world: A brief encounter", Journal of Neonatal Nursing, Vol. 20, No. 5, pp. 218-229, 2014. https://doi.org/10.1016/j.jnn.2014.03.002

[10] W. Chen, S. Dols, S.B. Oetomo, and L. Feijs, "Monitoring body temperature of newborn infants at neonatal intensive care units using wearable sensors", Proceedings of the Fifth International Conference on Body Area Networks, pp. 188-194, 2010. https://doi.org/10.1145/2221924.2221960

[11] S. Pouy, and M.m. Chehrzad, "Identification the best skin temperature probe attachment place in premature neonates nursed under radiant warmers in NICU: A diagnostic clinical trial study", Journal of Neonatal Nursing, Vol. 25, No. 2, pp. 69-73, 2019. https://doi.org/10.1016/j.jnn.2018.10.001

[12] W. Chen, S.B. Oetomo, L. Feijs, S. Bouwstra, I Ayoola, and S. Dols, "Design of an integrated sensor platform for vital sign monitoring of newborn infants at neonatal intensive care units", Journal of Healthcare Engineering, Vol. 1, No. 4, pp. 535-554, 2010. https://doi.org/10.1260/2040-2295.1.4.535

[13] D.P. Jones, "Biomedical sensors" Momentum press, LLC, New York, 2010.

[14] Y. Qi, H. Nguyen, K.S.E. Lim, W. Wang, and W. Chen, "Adsorptive Spin Coating To Study ThinFilm Stability in Both Wetting and Nonwetting Regimes", Langmuir, Vol. 35, No. 21, pp.69226928, 2019. https://doi.org/10.1021/acs.langmuir.9b00923.

[15] V. Thomsen, "Response time of a thermometer", The Physics Teacher 36, 540(1998), pp. 540-541. 1999. https://doi.org/10.1119/1.880128

[16] R.B. Knobel-Dail, "Preventing hypothermia in preterm infants: a program of research", Rwanda Journal, Vol. 2, No. 2, pp. 57-61, 2015. https://doi.org/10/0.4314/rj.v2i2.10F 
[17] A. Saleh, M.A. Mousa, A.M. Alfaifi, A.E. Negm, and M.O. Ali, "The impact of calibration on medical devices performance and patient safety", Biomedical Research, Vol. 29, No. 12, 2018. https://doi.org/10.4066/biomedicalresearch.29-18550

[18] E. Denton, A. Heng, and B. Fisher, "Wearable temperature sensing layout considerations optimised for thermal response", Application Report, 2018.

[19] Neotech, "NeoSmile ${ }^{\mathrm{TM}}$ temperature probe cover", 2020.

https://www.neotechproducts.com/product/neosmil e/.

[20] K. Bhatt, "Thermistors-development, manufacture and applications", IEE-IERE Proceedings-India, Vol. 11, No. 5, pp. 194-203, 1973.

[21] J. Webster, "Medical instrumentation: Application and design", The fourth edition, John Wiley \& Sons, 2009.

[22] I. Sinclair, "Sensors and transducers", The third edition, Newnes, 2001.

[23] N. Gupta, S. Sharma, I.A. Mir, and D. Kumar, "Advances in sensors based on conducting polymers", Journal of Scientific and Industrial Research, Vol. 65, No. 7, pp. 549-557, 2006. http://nopr.niscair.res.in/handle/123456789/4862.

[24] G. Pandey and A. Vora, "Open electronics for medical devices: state-of-art and unique advantages", Electronics, Vol. 8, No. 11, pp. 1256, 2019. https://doi.org/10.3390/electronics8111256

[25] A. Servati, L. Zou, Z.J. Wang, F. Ko, and P. Servati, "Novel flexible wearable sensor materials and signal processing for vital sign and human activity monitoring", Sensors, Vol. 17, No. 7, pp. 1622, 2017. https://doi.org/10.3390/s17071622

[26] Q. Li, L.N. Zhang, X.M. Tao, and X. Ding, "Review of flexible temperature sensing networks for wearable physiological monitoring", Advanced healthcare materials, Vol. 6, No. 12, pp. 1601371, 2017. https://doi.org/10.1002/adhm.201601371

[27] G. Lavenuta, "Negative temperature coefficient thermistors part I: Characteristics, materials, and configurations", Cornerstone Sensors, Inc. and Sensors Magazine, 1997.

[28] K.H. Koh, and C.W. Yu, "Comparing the accuracy of skin sensor temperature at two placement sites to axillary temperature in term infants under radiant warmers", Journal of Neonatal Nursing, Vol. 22, No. 4, pp. 196-203, 2016. https://doi.org/10.1016/j.jnn.2016.01.003
[29] S. Mazgaoker, I. Ketko, R. Yanovich, Y. Heled, and Y. Epstein, "Measuring core body temperature with a non-invasive sensor", Journal of thermal biology, Vol. 66, pp. 17-20, 2017. https://doi.org/10.1016/j.jtherbio.2017.03.007

[30] O. Bonner, K. Beardsall, N. Crilly, and J. Lasenby, "There were more wires than him': the potential for wireless patient monitoring in neonatal intensive care", BMJ innovations, Vol. 3, No. 1, pp. 12-18, 2017. http://dx.doi.org/10.1136/bmjinnov-2016$\underline{000145}$

[31] D. Ogoina, "Fever, fever patterns and diseases called 'fever' - A review", Journal of Infection and Public Health, Vol. 4, No. 3, pp. 108-124. https://doi.org/10.1016/j.jiph.2011.05.002

[32] M. Sund-Levander, C. Forsberg, and L.K. Wahren, "Normal oral, rectal, tympanic and axillary body temperature in adult men and women: a systematic literature review", Scandinavian journal of caring sciences, Vol. 16, No. 2, pp. 122-128, 2002. https://doi.org/10.1046/j.1471-6712.2002.00069.x

[33] C. Yan, J. Wang, and P.S. Lee, "Stretchable graphene thermistor with tunable thermal index", ACS nano, Vol. 9, No. 2, pp. 2130-2137, 2015. https://doi.org/10.1021/nn507441c

[34] C.-C. Huang, Z.-K. Kao, and Y.-C. Liao, "Flexible miniaturised nickel oxide thermistor arrays via inkjet printing technology", ACS applied materials \& interfaces, Vol. 5, No. 24, pp. 12954-12959, 2013. https://doi.org/10.1021/am404872j

[35] Y. Khan, M. Garg, Q. Gui, M. Schadt, A. Gaikwad, D. Han, N.A. Yamamoto, P. Hart, R. Welte, W. Wilson, S. Czarnecki, M. Poliks, Z. Jin, K. Ghose, F. Egitto, J. Turner, A.C. Arias, "Flexible hybrid electronics: Direct interfacing of soft and hard electronics for wearable health monitoring", Advanced Functional Materials, Vol. 26, No. 47, pp. 8764-8775,

2016. https://doi.org/10.1002/adfm.201603763

[36] V. Lebedev, E. Laukhina, V. Laukhin, A. Somov, A.M. Baranov, C. Rovira, and J. Veciana, "Investigation of sensing capabilities of organic bilayer thermistor in wearable e-textile and wireless sensing devices", Organic Electronics, Vol. 42, pp. 146-152, 2017. https://doi.org/10.1016/j.orgel.2016.12.034

[37] T.-H. Le, Y. Kim, and H. Yoon, "Electrical and electrochemical properties of conducting polymers", Polymers, Vol. 9, No. 4, pp. 150, 2017. https://doi.org/10.3390/polym 9040150 
[38] J.V. Thombare, M.C. Rath, S.-H. Han, and V.J. Fulari, "Synthesis of hydrophilic polypyrrole thin films by silar method", Materials Physical Mechanics, Vol. 16, pp. 118-125, 2013.

[39] R. Balint, N.J. Cassidy, and S.H. Cartmell, "Conductive polymers: towards a smart biomaterial for tissue engineering", Acta biomaterialia, Vol. 10, No. 6, pp. 2341-2353, 2014. https://doi.org/10.1016/j.actbio.2014.02.015

[40] Ye.P. Mamunya, V.V. Davydenko, P. Pissis, and E.V. Lebedev, "Electrical and thermal conductivity of polymers filled with metal powders", European Polymer Journal, Vol. 38, No. 9, pp. 1887-1897, 2002. https://doi.org/10.1016/S00143057(02)00064-2

[41] L. György, "Conducting polymers: A new era in electrochemistry", Springer, 2008.

[42] I. Bahadur, "Synthesis and characterisation of pure and doped conducting and Semiconducting materials", Theses, Department of Physics, University of Lucknow, 2015. http://hdl.handle.net/10603/44763
[43] G. Kaur, R. Adhikari, P. Cass, M. Bown, and P. Gunatillake, "Electrically conductive polymers and composites for biomedical applications", RSC Advances, Vol. 5, No. 47, pp. 37553-37567, 2015. https://doi.org/10.1039/C5RA01851J

[44] C. Lucarotti, C.M. Oddo, N. Vitiello, and M.C. Carrozza, "Synthetic and bio-artificial tactile sensing: A review", Sensors, Vol. 13, No. 2, pp. 1435-1466. 2013. https://doi.org/10.3390/s130201435

[45] L. Biagiotti, F. Lotti, C. Melchiorri, and G. Vassura, "An integrated approach to the design of complex robotic end-effectors", Proceedings 2003 IEEE/ASME International Conference on Advanced Intelligent Mechatronics (AIM 2003), Vol. 1, pp. 70-75, 2003. https://doi.org/10.1109/AIM.2003.1225074 